\title{
Doença granulomatosa mimetizando lesão gliomatosa
}

\section{Granulomatous Diseases may Mimic Glial Tumor Lesion}

\author{
José Maria Carri ${ }^{1}$ André de Macedo Bianco ${ }^{2}$ Alejandro Agustin Zoboli Carri ${ }^{3}$ \\ ${ }^{1}$ Neurocirurgião, Hospital Leforte - Grupo Bandeirantes, São Paulo, \\ SP, Brasil \\ 2 Neurocirurgião, Hospital Nove de Julho, São Paulo, SP, Brasil \\ Address for correspondence José Maria Carri, MD, Av. Angélica,546 \\ ap. 185, São Paulo, SP, Brasil 01228-000 (e-mail: jmcarri@me.com). \\ Arq Bras Neurocir 2016;35:89-96.
}

\section{Resumo \\ Palavras-Chave \\ - síndrome de imunodeficiência adquirida \\ - patógeno oportunista \\ - tumor glial}

Desde 1981 a aids tem estado presente em nossa sociedade. Como consequência, doenças infectocontagiosas e novos patógenos oportunistas têm desenvolvido novos comportamentos e adquirido novas virulências. Mesmo com a aquisição de novas tecnologias - como técnicas imunológicas, ressonância magnética (RM), tomografia computadorizada (TC), tomografia por emissão de pósitron (PET) e espectrometria -, existem desafios para o diagnóstico que incluem falsos negativos e positivos. Reportamos nossa experiência com paciente imunocomprometido e suas múltiplas infecções oportunistas, e juntamos casos com diferentes patógenos que mimetizam tumores de estirpe glial com resultados falsos positivos e negativos nas provas imunológicas, seja por comprometimento imunológico do hospedeiro, seja por provas cruzadas de colagenoses.

Since 1981 AIDS has been present in our society. Following it, controlled infection diseases and new opportunistic pathogen have raised different behavior and virulence. Even with the important technical advance such as immunologic assay, magnetic resonance (MRI), computed tomography $C T$, positron emission tomography (PET) and spectrometry there still exists a real challenge for diagnosis, including high levels of false negatives. We report in this work our experience with imunocompromised patients and their multiple opportunistic diseases and attach it different pathogens that may mimic tumoral glial diseases with false positive and negatives results in immunological assay, developed by host imunocompromised reactivity or by cross reaction of collagenosis desease.

\section{Introdução}

A aids (síndrome de imunodeficiência adquirida) constitui a primeira grande pandemia da segunda metade do século XX. ${ }^{1}$ Foi descrita em 1981 pelo Center for Disease Control (CDC), nos Estados Unidos.

Recebido

March 3, 2014

Aprovado

August 28, 2015

published online

February 16, 2016
Desde então, têm surgido patologias de origem infecciosa, controladas ou parcialmente controladas, modificando seu comportamento seja pelo aumento da virulência, seja pelo imunocomprometimento próprio dos pacientes portadores de aids. ${ }^{1-4}$ Apesar do avanço tecnológico dos exames de imagem, as variações evolutivas intrínsecas, e
DOI http://dx.doi.org/ 10.1055/s-0035-1570497. ISSN 0103-5355.
Copyright $(\underset{0}{ } 2016$ by Thieme Publicações License terms Ltda, Rio de Janeiro, Brazil




principalmente o comprometimento imunológico dos pacientes, podem levar a erros diagnósticos, mimetizando, principalmente, doenças tumorais de origem gliomatosa. Ao confrontar-nos com pacientes imunocomprometidos, devemos ampliar o espectro das pesquisas para patologias como: toxoplasmose, criptococose, paracocciodioidomicose, neurotuberculose, sífilis, borreliose, aspergilose, doença de Chagas (em zonas endêmicas), lesões metastáticas, sarcoidose e linfoma primário do sistema nervoso central (LPSNC). ${ }^{5-13}$

\section{Relato de Caso}

Paciente de 45 anos de idade, casado, motorista, hígido. Em abril de 2013, ingressa em serviço hospitalar apresentando, agudamente, disartria grave, acompanhada de crise convulsiva única. Realizado o primeiro atendimento e solicitada TC de encéfalo, foi liberado 24 horas depois, com diagnóstico de acidente vascular cerebral isquêmico (AVCI).

Após 15 dias, durante consulta em nosso serviço para dar continuidade ao tratamento, apresentava-se lúcido, contactante, com força preservada nos membros, interpretação adequada da palavra verbal e escrita, disartria. Queixava-se de dificuldade para deglutir devido a dor mal definida na região orofaríngea, de cefaleia incapacitante e refratária ao tratamento, acompanhada de náuseas e vômitos. A tomografia computadorizada de encéfalo mostrava área hipodensa na região temporal esquerda, acometendo o hipocampo, com efeito expansivo e edema digitiforme desproporcional, comprometendo o lobo temporal no seu terço anterior, estendendo-se para os núcleos da base e promovendo desvio da linha média.

Foi solicitada RM na urgência e realizada a internação para melhor pesquisa ( - Fig. 1). O exame radiológico apresenta na

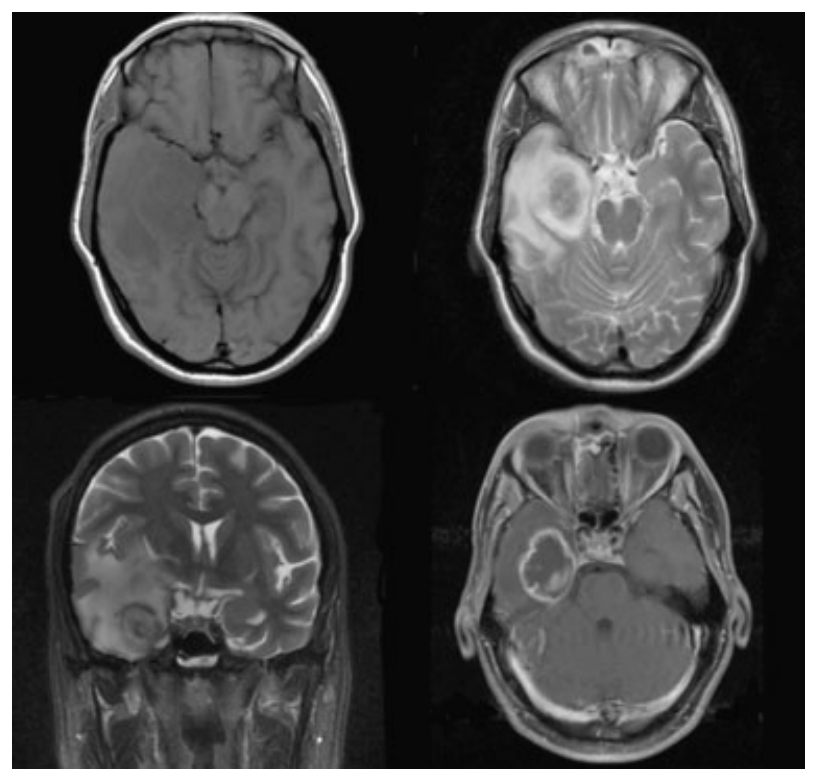

Fig. 1 Imagens ponderadas em T1-T2 (corte axial) mostrando área hipointensa com infiltrado temporal anterior e medial, T2 (corte coronal), T1 (corte axial) contrastada demostrando realce anelar com sinal sugestivo de necrose central. imagem ponderada em T1 área hipointensa acometendo o lobo temporal, porção anterior, o hipocampo parcialmente, com extensão aos núcleos da base.

A imagem ponderada em T2 demostra uma área hiperintensa, infiltrativa, acompanhada de lesão anelar que acomete porção medial do lobo temporal com centro hipointenso, podendo corresponder a necrose central. Na imagem ponderada em T1 contrastada, observamos realce anelar irregular na porção média e posterior do lobo temporal, com centro hipointenso, que são características de lesão de origem glial.

\section{Exames Laboratoriais}

- Hemograma: anemia normocítica normocrômica, Hb: 9,6; Hct: 30; plaquetas: 248.000; leucócitos: 3.500, sem desvio à esquerda.

- Sangue oculto nas fezes: negativo.

- Glicemia: 90; ureia: 28; creatinina: 1,35; coagulograma e perfil hepático dentro da normalidade para a faixa etária.

- Provas cardiológicas dentro da normalidade.

- Endoscopia digestiva alta: lesões esofágicas em pequeno número, sugestivas de candidíase esofágica.

\section{Tratamento Inicial}

Foi realizado tratamento medicamentoso, com corticoterapia, fenitoína e micostatina (solução oral), associado ao tratamento cirúrgico para retirada da lesão tumoral temporal profunda à direita. Atingindo o objetivo, pela via transcortical temporal, encontramos área de clivagem perfeitamente delimitada sem evidências macroscópicas de infiltração do parênquima adjacente.

Estruturalmente, a lesão apresentava características firmes e fibrelásticas, sem sangramento quando penetrada. Internamente, observamos discreta liquefação do seu conteúdo. Na porção posterior, em íntima relação com a borda anterossuperior da pirâmide petrosa, apresentava discreta aderência à dura-máter, estendendo-se para a fossa média em sentido medial. 0 material retirado foi encaminhado para análise anatomopatológica e testes imuno-histoquímicos.

Em função das características macroscópicas observadas, e dos resultados hematológicos e endoscópicos, foi solicitado teste de HIV, com resultado positivo na primeira amostra, confirmado na segunda. A seguir, realizamos TC de tórax com resultado normal, testes hematológicos para sífilis, toxoplasmose, paracoccidioidomicose e contagem de linfócitos CD4 e CD8.

O resultado anatomopatológico parcial descreve infiltração inflamatória mista com predomínio perivascular e áreas de necrose. Não foram identificados bacilos resistentes a álcool-ácido ou fungos pelos métodos Ziehl-Neelsen e Grocott et al, e foi descartada a hipótese de doença de origem tumoral. Foi solicitada extensão do estudo para pesquisa de toxoplasma, citomegalovírus (CMV) e herpes (-Tabela $\mathbf{1}$ ).

Na vigência de melhora parcial das lesões esofágicas, foi realizado novo exame endoscópico com biópsia de lesões remanescentes rebeldes ao tratamento com micostatina, 
Tabela 1 Relatório imuno-histoquímico do espécime patológico.

\begin{tabular}{|l|l|l|}
\hline Anticorpo & Clone & Interpretação \\
\hline Toxoplasmose & policlonal & $(+)$ \\
\hline CMV & CCH2 + DDG9 & $(-)$ \\
\hline Herpes HSVI/II & policlonal & $(-)$ \\
\hline CD3 & F7.2.38 & $(+)$ em linfócitos \\
\hline CD20 & L26 & $(+)$ em linfócitos \\
\hline Ki-67 & MiB-1 & $(+)$ em linfócitos reacionais \\
\hline O perfil imunológico, em conjunto com achados morfológicos, favorece o diagnóstico de neurotoxoplasmose \\
\hline
\end{tabular}

Abreviações: $C C H 2 / D D G 9$, anticorpo anticitomegolovius; $C D 3$, grupamento de diferenciação 3; $C D 20$, antigeno linfocito B; CMV, citomegalovirus; $\mathrm{HSVVI} / \mathrm{Il}$, herpes virus; Ki-67/MiB-1, anticorpo monoclonal.

com resultado positivo para úlcera esofágica por CMV (-Fig. 2, -Tabela 2).

Exame tomográfico de controle após 7 dias não identificou sinais de hipertensão intracraniana e edema reacional perilesional. Com os resultados preliminares dos testes positivos para toxoplasmose, foram introduzidas: pirimetamina, $50 \mathrm{mg}$ por dia; sulfadiazina, $1 \mathrm{~g}$ de 6 em $6 \mathrm{~h}$, e leucovorina, $15 \mathrm{mg}$ por dia, acrescentando
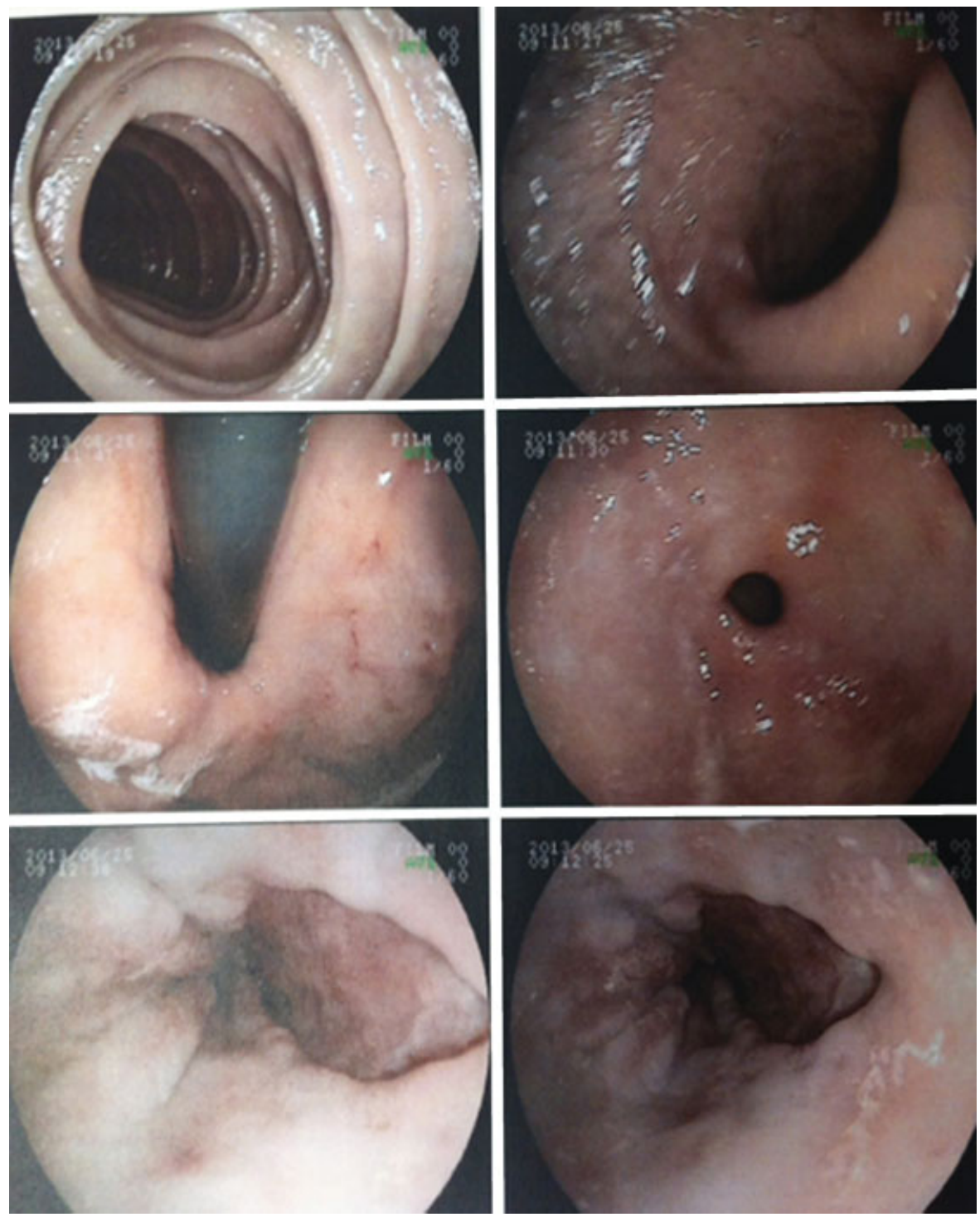

Fig. 2 Estudo endoscópico de úlcera esofágica e resultado imuno-histoquímico positivo para CMV. 
92 Doenças granulomatosas Carri et al.

Tabela 2 Estudo endoscópico de úlcera esofágica e resultado imuno-histoquímico positivo para CMV

\begin{tabular}{|l|l|l|}
\hline Anticorpo & Clone & Interpretação \\
\hline CMV & CCH2 + DDG9 & $(+)$ nas células de interesse \\
\hline Herpes HSVI/VII & policlonal & $(-)$ nas células de interesse \\
\hline Conclusão: positivo para citomegalovirus & \\
\hline
\end{tabular}

Abreviações: CCH2/DDG9, anticorpo anticitomegalovirus; CMV, citomegalovirus; HSVI/vVI, herpes virus.

ganciclovir para o tratamento do processo ulcerativo esofágico por CMV.

\section{Resultados Laboratoriais Evolutivos}

- Hemograma: eritrócitos: 3,9; Hb: 10,1; Hct: 29,4; plaquetas: 135.000; leucócitos: 4.040, sem desvio à esquerda.

- Glicemia: 89; ureia 35; creatinina: 1,61.

- Perfil hepático: TGP: 52; TGO: 77; GGT: 65.
- Eletroforese de proteínas: proteínas totais: 7,2; albumina: 3,59 .

Imuno-ensaios

- Toxoplasmose: IgG: > $650 \mathrm{UI} / \mathrm{mL}$; IgM: 0,2.

- Látex criptococo: não reagente.

- Blastomicose, anticorpos: não reagente.

- Mycobacterium tuberculosis: não detectado.

- Sífilis, anticorpos específicos: não reagente.

Tabela 3 Parâmetros de provas laboratoriais na vigência do início de tratamento

\begin{tabular}{|c|c|c|c|c|}
\hline & $21 / 03 / 2013$ & $04 / 06 / 2013$ & $24 / 06 / 2013$ & $15 / 07 / 2013$ \\
\hline & & Pirimetamina/ sulfadiazina & Bactrim $^{\mathrm{TM}} /$ cymevir $^{\mathrm{TM}}$ & Bactrim $^{\mathrm{TM}} /$ retrovirais \\
\hline Eritrócitos & 3,53 & 3,93 & 3,55 & 3,34 \\
\hline $\mathrm{Hb}$ & 9,6 & 10,1 & 9,3 & 8,9 \\
\hline Hct & 30,1 & 29,4 & 27,9 & 26,1 \\
\hline Leucócitos & 3.500 & 4.040 & 2.300 & 2.400 \\
\hline Ureia & 28 & 35 & 21 & 38 \\
\hline Creatinina & 1,35 & 1,61 & 1,3 & \\
\hline Plaquetas & 152.000 & & 52.000 & 122.000 \\
\hline HIV & + & & & \\
\hline PCR & 4,09 & & & \\
\hline Western B. & reagente & & & \\
\hline TGO & 14 & 77 & 25 & 96 \\
\hline TGP & 29 & 52 & 32 & 121 \\
\hline GGT & 60 & 65 & 60 & 152 \\
\hline Amilasa & 76 & & & \\
\hline F. alacalina & 68 & & 81 & 128 \\
\hline Proteína & & 7,2 & & \\
\hline Albumina & & 3,59 & & \\
\hline CD4 & & $4,6 \% / 5,5 \mathrm{~mm}$ & & \\
\hline CD8 & & $69,5 \% / 368 \mathrm{~mm}$ & & \\
\hline Rel. CD4-CD8 & & 0,02 & & \\
\hline Sífilis Ac. & & não reagente & & \\
\hline Toxopl. IgG & & sup $650 \mathrm{Ui} / \mathrm{mL}$ & & \\
\hline Toxopl IgM & & 0,2 & & \\
\hline Criptococo & & não reagente & & \\
\hline Blastomicose & & não reagente & & \\
\hline M. tuberculosis & & não detectado & & \\
\hline
\end{tabular}

Abreviações: Ac, anticorpo; ALB, albumina; CD4, grupamento de diferencia ,ão 4; CD8, grupamento de diferencia ,ão 8; GGT, gamaglutamiltransferase; Hb, hemoglobina; Hct, hematócrito; PCR, proteína C reativa; Prot, proteína; TGO, transaminase glutámico oxalacética; TGP, transaminase glutámico pirúvica. 
- Linfócitos T-CD8: 69,5\%; absoluto: 368.

- Linfócitos T auxiliar CD4: 1,6\%; absoluto: 5,5/mm.

Avaliado o baixo índice de CD3-CD4, adiamos a introdução de antirretrovirais para evitar recuperação imunológica com baixo controle da infecção prevalente, o que acarretaria piora do quadro clínico por componente reacional imunológico reativado e não pela progressão do patógeno diagnosticado (-Tabela 3).

\section{Discussão}

As doenças infectocontagiosas que têm a capacidade de desenvolver lesões granulomatosas podem mimetizar, ao exame radiológico, lesões tumorais de origem glial ou metastática.

O comportamento dessas patologias vem mudando seja na sua virulência, seja nas suas características evolutivas, após o aparecimento da aids. Por isso, os pacientes devem ser investigados com maior acurácia, ampliando as metodologias diagnósticas.

Testes laboratoriais utilizados no sangue periférico e estudos do líquido cefalorraquidiano (LCR) podem atingir o objetivo diagnóstico quando positivos; porém, quando negativos, devem ser avaliados outros exames complementares, como TC, RM e espectroscopia, na tentativa de introduzir o tratamento medicamentoso mais apropriado.

Todos os testes que incluem imunocomplexos (ELISA, FC, IFI, Sabin, Feldman) têm alta especificidade e sensibilidade relativa. Quando confrontados os resultados em pacientes imunocomprometidos com CD4 $<100$, a sensibilidade diminui, aumentando falsos negativos, como no caso acima descrito.

Nos casos em que as provas sorológicas foram negativas, e nos de suspeita de infecção ou infestação, devem ser realizada, sempre que possível, análise do LCR, que também pode ter resultados inespecíficos. Nestes casos, a TC ou RM foram o método diagnóstico não invasivo mais útil, porém ainda limitado.

Os achados de imagem refletem a interação entre a resposta imune do hospedeiro, o agente infecioso e o grau de dano à barreira hematoencefálica, pois a imagem determinada pelo mesmo patógeno apresenta diferentes padrões de comportamento em imunocompetentes. Tem sido demonstrado que um dos aspectos de interação agente infeccioso-hospedeiro é o padrão de captação anelar do contraste, não representando necessariamente a cápsula de um abscesso. Isto indica apenas que a infecção é localizada e que alguns pacientes imunocomprometidos conseguem mobilizar suas defesas e impedir a propagação do processo infeccioso. Portanto, nos indivíduos com aids, a resposta imune inadequada reflete-se no padrão tomográfico alterado, o que não ocorre com os imunocompetentes.

Em imunocomprometidos, a toxoplasmose ${ }^{5,6}$ cerebral e as meningites criptococósicas e tuberculosas representam $79,4 \%$ das complicações observadas. Dentre estas, 25-80\% correspondem a neurotoxoplasmose.
O perfil sorológico dos pacientes com aids e neurotoxoplasmose é semelhante ao da população geral, com infecção inativa. Anticorpos da classe IgM anti-Toxoplasma gondii não são habitualmente detectados, e os da classe $\operatorname{IgG}$ não discriminam infecção latente (crônica) da infecção ativa.

A existência de $\operatorname{IgG}$ indica ter havido contato prévio, porém não confirma doença ativa. Nos doentes imunocomprometidos, a clínica semiológica e o ciclo evolutivo da doença podem apresentar-se distorcidos e levar a erros diagnósticos.

Em casos de toxoplasmose, devemos investigar a possibilidade de existência concomitante de doenças reumatológicas com anticorpos antinucleares (ANCA), podendo dar leitura positiva ou, na competência de imunocomplexos $\mathrm{IgG}$, falsos negativos.

Na maioria dos casos, portanto, o diagnóstico da neurotoxoplasmose é presuntivo, baseado nos achados de TC ou de RM e na presença de anticorpos IgG específicos no soro, uma vez que em apenas 3-6\% dos casos de reativação não se detectam tais anticorpos. A confirmação se faz diante da resposta à terapêutica empiricamente instituída, que ocorre, em geral, entre 7 e 14 dias.

Em 60-70\% dos pacientes, há casos de lesões múltiplas e bilaterais que comprometem principalmente os gânglios da base, a substância cinzenta subcortical e branca. Ocasionalmente, as lesões podem ser únicas ou infratentorias (-Fig. 3).

$\mathrm{Na}$ criptococose os resultados das provas diagnósticas imunológicas apresentam comportamento semelhante ao das acima detalhadas, porém as técnicas de isolamento do fungo nos permitem melhor diagnóstico.

Na prática, devemos manter o foco em duas cepas: neoformans e gattii. Contudo, o ser humano está exposto a outras cepas (39 espécies) consideradas patógenos emergentes quando nos referimos a pacientes imunocomprometidos.

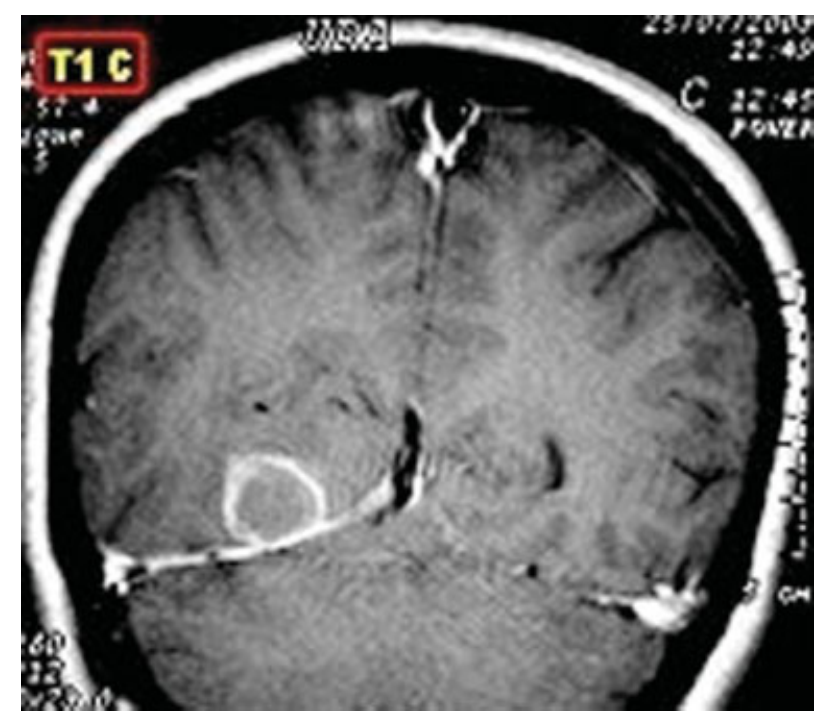

Fig. 3 Toxoplasmose Imagem ponderada em T1 (corte coronal) contrastada, apresentando realce anelar e perilesional e base de inserção tentorial. Imagem cedida pela FMC-UNICAMP. 
Na presença de fator reumatoide (FR) os testes para criptococose podem ter leitura falsa positiva. Os falsos negativos se apresentam com títulos baixos de antígeno, presença de imunocomplexos, presença do fenômeno de prozona, ou com criptococo com pouca cápsula ou não capsulados. ${ }^{7} \mathrm{Na}$ vigência de HIV, devemos incluir no diagnóstico a cepa gattii responsável pelo criptococoma. Este último prevalece em pacientes imunocompetentes e sua localização intraparenquimatosa pode dar leitura de falso negativo.

Na reconstituição imune, o paciente pode evoluir com piora do quadro clínico e mudanças dos resultados nas provas imunológicas do LCR e radiológicas. Isto se deve à diminuição da carga viral e ao aumento dos linfócitos T CD4/ microL, podendo levar ao óbito do paciente, não pela falência de tratamento. ${ }^{7}$

A sífilis é uma doença infecciosa, sexualmente transmissível, causada pela espiroqueta Treponema pallidum. A sensibilidade dos testes sorológicos não treponêmicos (VDRL) pode estar comprometida. Destacamos que estes testes mensuram IgG-IgM contra o material lipídico liberado no soro devido a mitocôndrias lesadas do hospedeiro. Os testes não treponêmicos (FTA-ABS) detectam anticorpos direcionados contra o antígeno anticardiolipina-lecitina do próprio patógeno. Pacientes com infecção pelo HIV apresentam tanto anticorpos anticardiolipina-lecitina como gamapatia policlonal devido à ativação policlonal de celulas $B$ induzidas pelo próprio HIV. Desta forma, testes positivos para teste rapido não treponémico (RPR) ou VDRL podem não representar infecção ativa pela sífilis assim como testes positivos em LCR de provas treponêmicas, não confirmam infecção do SNC. A prevalência desta doença é maior em pacientes HIV-positivos, quando comparados com HIVnegativos. Além disso, muitos estudos mostram um curso clínico mais rápido e agressivo em pacientes coinfectados, podendo a doença evoluir mais precocemente e, em maior percentual, para o acometimento do SNC, além de maior falha no tratamento ou recaída da infecção. Outro aspecto relevante são as alterações em testes sorológicos para sífilis, relacionados tanto à sororreativação (por ativação policlonal inespecífica de linfócitos induzida pelo HIV) quanto à sororreversão (por falha na produção dos anticorpos antitreponêmicos devido ao comprometimento progressivo da função imune). Contudo, nesses pacientes é melhor assumir que um teste reativo não trepomênico indicaria doença ativa factível de tratamento preventivo imediato $^{2,8}$ (-Fig. 4).

A doença de Chagas (Trypanosomas Cruzi), transmitida através das fezes do carrapato, apresenta como zonas endêmicas a Argentina, o Paraguai, Uruguai e Brasil. O comprometimento no sistema nervoso central se apresenta na forma do chagoma ou meningoencefalite difusa. O chagoma cerebral constitui lesões focais, geralmente múltiplas; porém, também de apresentação única com área de necrose central. Estas lesões são indistinguíveis clínica e radiologicamente da toxoplasmose. Os granulomas chagásicos captam contraste, formando um anel periférico com importante edema perilesional e efeito expansivo.,



Fig. 4 RM mostrando lesão expansiva extra-axial localizada na superfície dos polos frontal e temporal esquerdos, importante edema perilesional, com intensa impregnação pelo contraste paramagnético, inclusive com impregnação meníngea. Imagem cedida por Teixeira RO (2001). ${ }^{4}$

A tuberculose $(\mathrm{Tb})$ pode adotar três formas cínicas: meningoencefalite (95\%), tuberculoma intracerebral (2$4 \%)$, e abscessos cerebrais (0,5-2\%). Geralmente, são lesões múltiplas que comprometem a substância branca periventricular, espontaneamente hiperintensas em $\mathrm{T} 2$, sem efeito expansivo e sem realce quando administrado contraste. A liquefação caseosa origina os abscessos cerebrais tuberculosos, que se apresentam geralmente únicos, com zona 


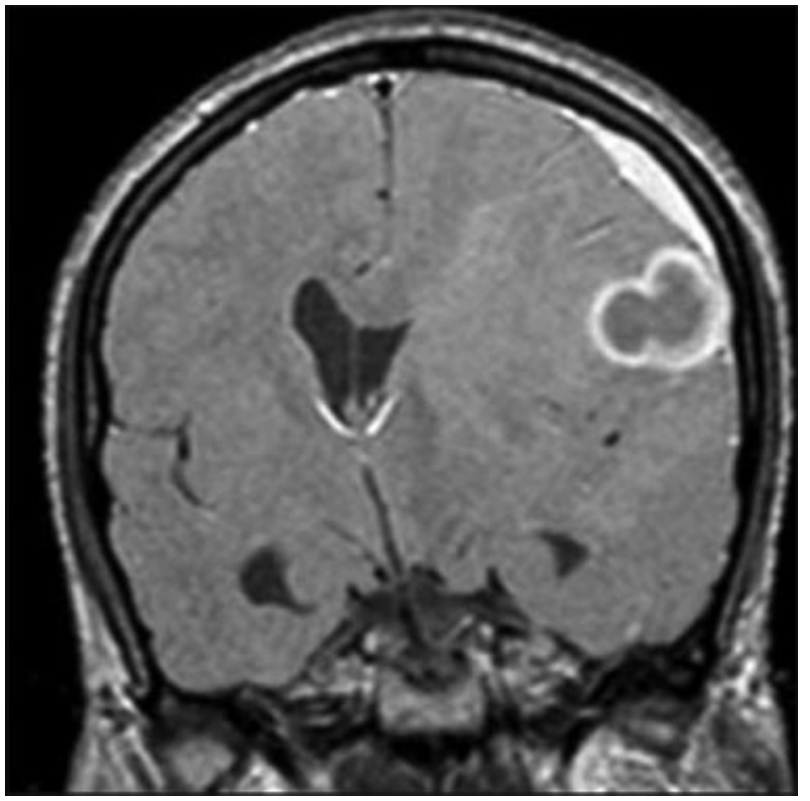

Fig. 5 Tuberculose. Imagem cedida pela FMC-UNICAMP.

central hipodensa, reforço periférico ao injetar contraste, com efeito de massa e edema perilesional. A presença de paredes grossas e contorno lobulado reforça a suspeita de lesão tuberculosa. A identificação laboratorial da Tb é dificil, mais ainda em pacientes imunodeprimidos sem lesão aparente do parênquima pulmonar ou com tuberculose latente. Após a soroconversão, o risco de ativação duplica após 1

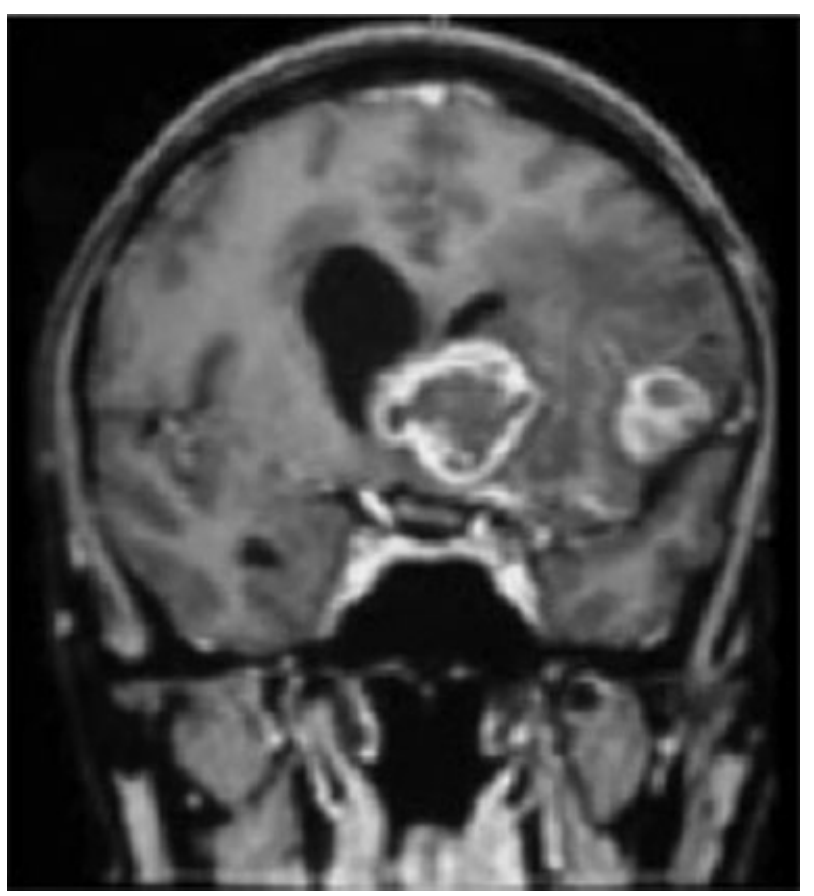

Fig. 6 RM (corte coronal) em T1 evidenciando lesão expansiva, captante de contraste após injeção de gadolínio, em forma anelar, no hemisfério esquerdo. Paracoccidioidomicose. Imagem cedida pelo Cunha (2012). ${ }^{12}$

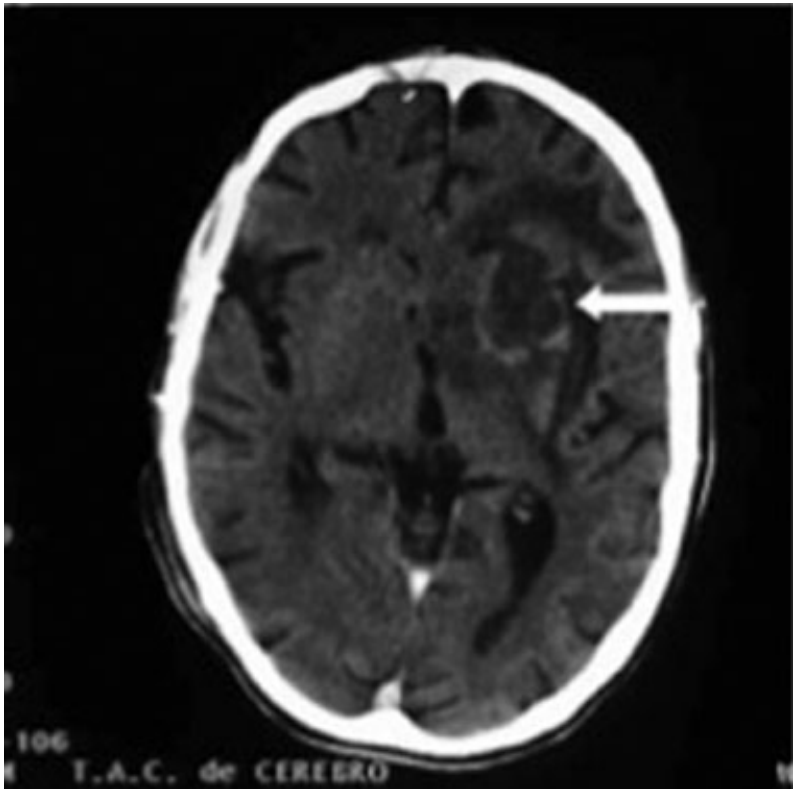

Fig. 7 TC com lesão única, sobre sustância branca periventricular esquerda, com reforço ao contraste, edema perilesional e efeito de massa a LPSNC (seta). Imagem cedida pela Revista Argentina de Radiologia.

ano. No teste intradérmico (tuberculina), existe a possibilidade de falsos positivos por microbactérias não tuberculosas ou prévia BCG. Falsos negativos podem ocorrer por elevado imunocomprometimento ou erros de interpretação na leitura ${ }^{10,11}$ (-Fig. 5).

\section{Paracoccidioidomicose}

Inespecificidade de sintomas, baixa sensibilidade dos testes diagnósticos, falta de infecção prévia e ocorrência isolada da neuro paraccocidiodomicose (NPCM) são fatores que tornam o diagnóstico da NPCM difícil.

A análise do LCR tem baixa sensibilidade e especificidade, e a pesquisa do Paracoccidioides Brasiliensis raramente é positiva, seja por cultura ou exame direto. Dependendo do nível de comprometimento das meninges, o líquor pode estar normal ou alterado.

No diagnóstico diferencial da forma granulomatosa de NPCM, deve-se incluir toxoplasmose, neoplasias - particularmente, gliomas malignos e tumores metastáticos -. tuberculose, abscessos bacterianos, neurocisticercose, além de outras micoses como criptococose e histoplasmose. $\mathrm{O}$ diagnóstico é feito principalmente pela análise anatomopatológica $^{12,13}$ (-Fig. 6).

O linfoma primário do sistema nervoso central (LPSNC) constitui a neoplasia de maior comprometimento na aids. Sua incidência oscila entre 3-4\%, localizando-se preferencialmente em substância branca periventricular, corpo caloso, tálamo e região subependimária. O diagnóstico diferencial de maior importância é com a toxoplasmose, devido à semelhança na apresentação clinica, aspecto das imagens e ausência de resultados positivos das provas laboratoriais $^{3}$ (-Fig. 7). 


\section{Conclusão}

O diagnóstico de doenças granulomatosas em paciente imunocomprometido, com queda grave do sistema de defesa, nos obriga a multiplicar o esforço diagnóstico, como demostrado ao longo do relato de caso, para diminuir o leque de doenças oportunistas que possam acometê-lo. Assim, ao abrir mão dos exames subsidiários devemos tratar empiricamente as possíveis patologias, submetendo o paciente a medicamentos nefrotóxicos, hepatotóxicos ou mielodepressivos e retardando o início do resgate imunológico.

\section{Referências}

1 Puccioni M, Favoreto AC, André C, Peixoto CA, Novis SAP. Acquired immunodeficiency syndrome: analysis of neurologic complications in 44 cases. Arq Neuropsiquiatr 1989;47(4):385-391

2 Fonseca MFS, Silva ML, Neves S. Discordância entre testes sorológicos para sífilis em pacientes HIV-positivos: perda de anticorpos treponêmicos? J Bras Patol Med Labo 2002; 38(3): 217

3 Corti M, Villafañe MF, Palmieri O, Yampolsky C, Millet G. Aporte de las neuroimágenes al diagnóstico del compromiso del sistema nervioso central en la enfermedad HIV/sida. Rev Argent Radiol 2007;71(1):39-46

4 Livramento JA, Machado LR, Moreno-Carvalho OA, Lacaz CS, Spina-França A. Cerebrospinal fluid in infection of the central nervous system by yeasts of the genus Candida: analysis of 11 cases. Arq Neuropsiquiatr 1989;47(3):332-336
5 Cantos GA, Prando MD, Siqueira MV, Teixeira RM. Toxoplasmose: ocorrência de anticorpos antitoxoplasma gondii e diagnóstico. Rev Assoc Med Bras 2000;46(4):335-341

6 Borges AS, Figueiredo Jde C. [Detection of anti-Toxoplasma gondii IgG, IgM and IgA immunoglobulins in the serum, cerebrospinal fluid and saliva of patients with acquired immunodeficiency syndrome and neurotoxoplasmosis]. Arq Neuropsiquiatr 2004; 62(4):1033-1037

7 de Queiroz JPAF, Sousa FDN, Lage RA, de Alencar Izael M, dos Santos AG. Criptococose - uma revisão bibliografica. Acta Veterinatia $2008 ; 2(2): 32-38$

8 Teixeira RO, Piekala C, Castro F, Dias MY, Costa JM, Teixeira EB. Neurossífilis gomatosa: Relato de caso. Arq Bras Neurocir. 2001; 20(3/4):110-114

9 Pittella JE. Central nervous system involvement in Chagas' disease. An updating. Rev Inst Med Trop Sao Paulo 1993;35(2):111-116

10 Nadvi SS, Nathoo N, Annamalai K, van Dellen JR, Bhigjee AI. Role of cerebrospinal fluid shunting for human immunodeficiency viruspositive patients with tuberculous meningitis and hydrocephalus. Neurosurgery 2000;47(3):644-649, discussion 649-650

11 Pimentel ML, Alves SM, Novis SA, Brandão RZ, Belo Neto E. [Intracranial tuberculomas developing during treatment of pulmonary tuberculosis: case report]. Arq Neuropsiquiatr 2000;58 (2B):572-577

12 Cunha Mda C, Onuki CA, Aymone N, de Assis JF, Piekala C, Pletz ALB. Neuroparacoccidioidomicose mimetizando mestástase cerebral: relato de caso e revisão de literature. J Bras Neurocir 2012; 23(3):226-233

13 Costa MAB, Carvalho TN, de Araújo Júnior CR, Borba AOC, Veloso GA, Teixeira KS. Manifestações extrapulmonares da paracoccidioidomicose; Extra-pulmonary manifestations of paracoccidioidomycosis. Radiol Bras 2005;38(1):45-52 